\title{
Three-dimensional intraoperative imaging with 0 -arm to establish a working trajectory in percutaneous endoscopic lumbar discectomy
}

\author{
Shu Wei, Wei Tao, Hongwei Zhu, Yongjie Li \\ Xuanwu Hospital, Capital Medical University, Beijing, China
}

Videosurgery Miniinv 2015; 10 (4): 555-560

DOI: $10.5114 /$ wiitm.2015.55845

\begin{abstract}
Introduction: Successful percutaneous endoscopic lumbar discectomy (PELD) requires an appropriate working trajectory. Due to the complexity of spinal anatomy, this is difficult to verify with conventional 2-dimensional fluoroscopy. Aim: Here we assessed the feasibility and utility of the O-arm for establishing the working trajectory for PELD.

Material and methods: We retrospectively reviewed the records of 89 patients with lumbar disc herniation who underwent PELD using the O-arm. The working trajectory was evaluated with standard fluoroscopic images or 3-dimensional, volumetric computed tomography scan. Based on the detail provided by the multiplanar view, we confirmed the ideal working trajectory and adjusted the surgical approach accordingly.

Results: At the 12-month follow-up, based on MacNab's criteria, 85.9\% of patients showed an excellent or good outcome. There were no major complications.

Conclusions: The O-arm provides detailed multiplanar intraoperative high-quality imaging for PELD, and enables the surgeon to ascertain the surgical anatomy, determine the optimal working trajectory, and improve the accuracy of surgery.
\end{abstract}

Key words: low back pain, intraoperative imaging, O-arm, disc herniation, percutaneous endoscopic lumbar discectomy.

\section{Introduction}

Percutaneous endoscopic lumbar discectomy (PELD) was first described by Kambin and Gellman in 1983 [1]. With the development of endoscopic instruments and surgical techniques, the procedure has gradually emerged as a favored minimally invasive technique for treating lumbar disc herniation. Compared with microlumbar discectomy, PELD not only better preserves the normal para-spinal structures, but also provides shorter rehabilitation and fast return to daily activities [2].

However, the risk of incomplete removal of disc fragments is a major concern in the use of PELD, particularly in cases of high-grade migrated lumbar disc herniation. Since endoscopic surgery only exposes a narrow field around the posterior spine, an improper work trajectory can lead to disc fragment residue. The success of PELD depends on an accurate surgical trajectory and the operator's knowledge of spinal anatomy [3].

Conventional fluoroscopy is routinely used to evaluate the work trajectory prior to discectomy, but its 2-dimensional field hampers the surgeon's comprehensive understanding of the spinal anatomy in 3 dimensions [4]. A more advanced intraoperative imaging technique is intraoperative cone beam computed tomography (CT) scanning (O-arm), which allows either standard fluoroscopic images or a full 360-degree scan with 3-dimensional (3D) volumet-

\section{Address for correspondence}

Prof. Yongjie Li, Beijing Institute of Function Neurosurgery, Xuanwu Hospital, Capital Medical University, 45 Changchun St,

Xicheng, 100053 Beijing, China, phone: +86 1861818 2019, e-mail: liyongjie1999@163.com 
ric reconstructions. The $\mathrm{O}$-arm has become widely available to aid intraoperative decisions, especially in pedicle screw positioning for spinal trauma surgery [5].

Herein, we describe the utility of the O-arm for determining the working trajectory in PELD. To our best knowledge, this method has not been described previously.

\section{Aim}

We retrospectively reviewed PELD procedures to assess the feasibility and utility of the O-arm (Medtronic) for establishing the working trajectory. We present intraoperative 3D images of the working cannula and discography.

\section{Material and methods}

Between March 2012 and November 2013, 89 consecutive patients underwent PELD with assistance of the O-arm. The criteria for PELD were lower limb radiculopathy with or without associated back pain, presence of a nerve root tension sign, failure of conservative treatment for 3 months, and corresponding finding on clinical and radiological examination. Patients who had segmental instability or severe central canal stenosis were excluded. All patients were informed that the O-arm would be used as the intraoperative imaging technique, and each provided signed consent.

The O-arm was initially placed with an open gantry as an open "C". After the patient was positioned prone for a transforaminal approach, the gantry

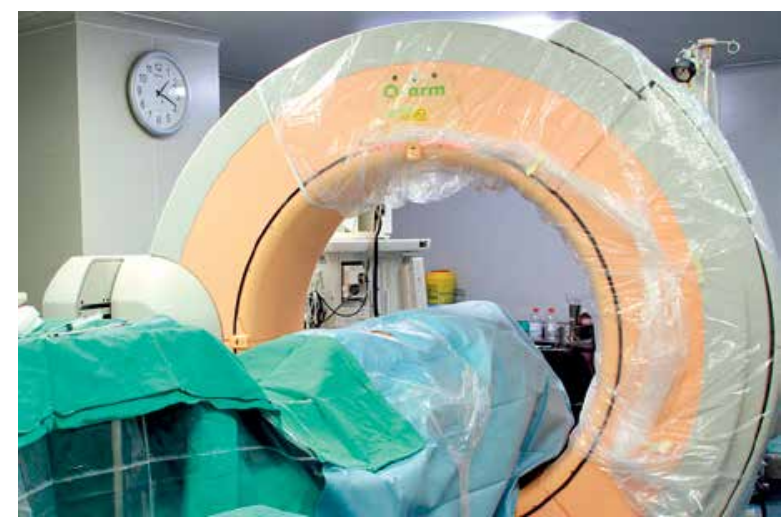

Photo 1. The typical operative setup of the $\mathrm{O}$-arm in a PELD procedure. The patient is positioned in the center of the coil, which is draped with sterile translucent plastic was draped and the 2D fluoroscopy feature used to center it optimally for 3D scanning and to verify operative levels. The machine was covered with sterile plastic (Photo 1). The surgical procedure was conducted under local anesthesia. Surgical planning of the working trajectory was carried out preoperatively, based on CT or magnetic resonance imaging (MRI) in the Image Workstation. After sterile preparation around the skin entry point, an 18-gauge spinal needle was introduced to the target. The O-arm was used for repetitive 2D fluoroscopy during the procedure, anteroposterior and lateral, to control the progression of the spinal needle.

The spinal needle was inserted into the disc and an intraoperative discogram was conducted with a 2-ml mixture of radio-opaque dye, indigo carmine and normal saline. Sequential reamers were used to enlarge the foramen by removing the ventral aspect of the superior facet. The beveled working cannula was then placed over the sequential dilators. Once the working cannula was in place, an intraoperative 3D scan with the O-arm was performed to ensure satisfactory positioning of the working cannula and to assess the degree of bony resection. The dye leaks through the tear in the annulus in the epidural space and thereby identifies the herniated fragment and annual tear fissure (Photos 2-3).

If the positioning of the working cannula was appropriate, the $\mathrm{O}$-arm was removed and no further imaging was carried out intraoperatively. If revision was required, a second 3D scan was obtained intraoperatively to confirm the correct cannula placement. The discectomy was then started by the Yeung endoscopic spine system (Richard Wolf, Knittlingen, Germany) as usual, in accordance with the standard protocol [6].

\section{Results}

Among the 89 patients, 4 patients were lost to follow-up and 85 patients were followed for a minimum of 12 months (Table I). Based on the modified MacNab's criteria (Table II), the outcomes of 73 (85.9\%) patients were excellent or good, 8 (9.4\%) were fair, and 4 (4.7\%) were not improved [7]. The 10-point visual analogue scale of pain improved from a mean score of 7.1 pre-operatively to 1.9 post-operatively. There were no complications associated with instrumentation placement or use of the o-arm. 

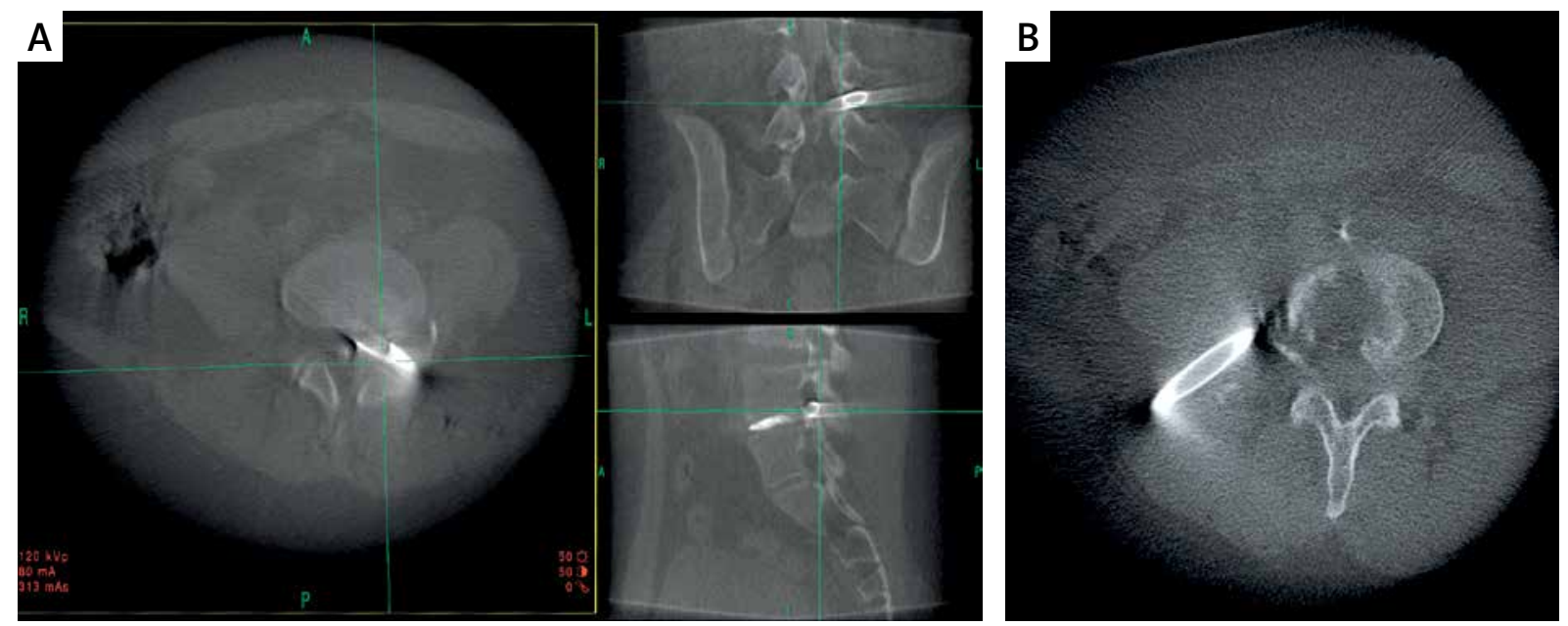

Photo 2. Intraoperative image taken utilizing the O-arm. A - The multiplanar image shows an appropriate working cannula. B - An axial image showed that the left working cannula was misplaced laterally

\section{Discussion}

This retrospective study assessed the use of the O-arm for establishing the working trajectory for PELD. We reviewed the outcomes of 89 patients who underwent PELD using the O-arm. At the 12-month follow-up, patients' VAS scores had significantly improved and more than $95 \%$ had achieved outcomes that were fair or better, with no major complications.

Inserting a working trajectory into the annulus is a universal feature of all endoscopic lumbar discectomies, and is the most important step. Using the O-arm to aid placement of the working cannula has several advantages over conventional fluoroscopy. For example, the O-arm provides a multiplanar view that better details the working trajectory, including the angle of the surgical trajectory in the axial view, degree of bone resection, and discogram. Thus, the $\mathrm{O}$-arm enables us to achieve a working trajectory in PELD with unprecedented accuracy. Not incidentally, the $3 \mathrm{D}$ volumetric reconstruction system allows better training of unskilled surgeons.

Establishing the correct working trajectory will create the optimal surgical field for PELD, and is the key to a successful procedure. However, it is difficult to ascertain the correct path of the trajectory, as the guide needle is affected by tissue and osteophytosis of the facet joint. Although the trajectory may appear to be satisfactory in one plane of a 2D projection, in another plane it may be obviously improper. Without suitable visual assistance by intraoperative imaging, the misplaced working cannula may compress the exiting nerve root close to the neural fora- men, which could result in dysesthesia and muscle weakness. This risk can be avoided by confirming the trajectory through the foraminal view in the O-arm, and estimating the distance from the nerve root to the working cannula [8]. Some surgeons prefer the foraminoplastic technique for undercutting the face joint bone to widen and decompress the exit nerve root, especially for lumbar disc herniation at the L5S1 level [9-11]. If so, then in the multiplanar view of the $\mathrm{O}$-arm the quality of the bony resection can be checked [12, 13].

Compared with $\mathrm{CT}$ alone, the surgeon can gain more information regarding the herniated status of the disc from the discogram in the O-arm. In the 3D view, the volume, location, and tear site of disc fragments are revealed, which helps determine the proper endoscopic surgical approach route to the disc material, especially for migrated herniation. Discography also has a specific role in PELD, to differentiate the intervertebral pathologic nucleus and identify the origin of pain [14]. Disc herniation is not the only source of low back pain; the ingrowth of granulation tissue with annular tears may also be a pathologic mechanism $[15,16]$. Disc granulation should be coagulated through bipolar radio frequency or laser. This method was reported to improve discogenic back pain $[17,18]$. Low-dose CT discography's accuracy in the assessment of disc disruption is superior to fluoroscopic discography [19]. The surgical route can be adjusted according to the site of the annular tear and herniation, to ablate granulation around the annular fissure and extract disc fragments safely. 

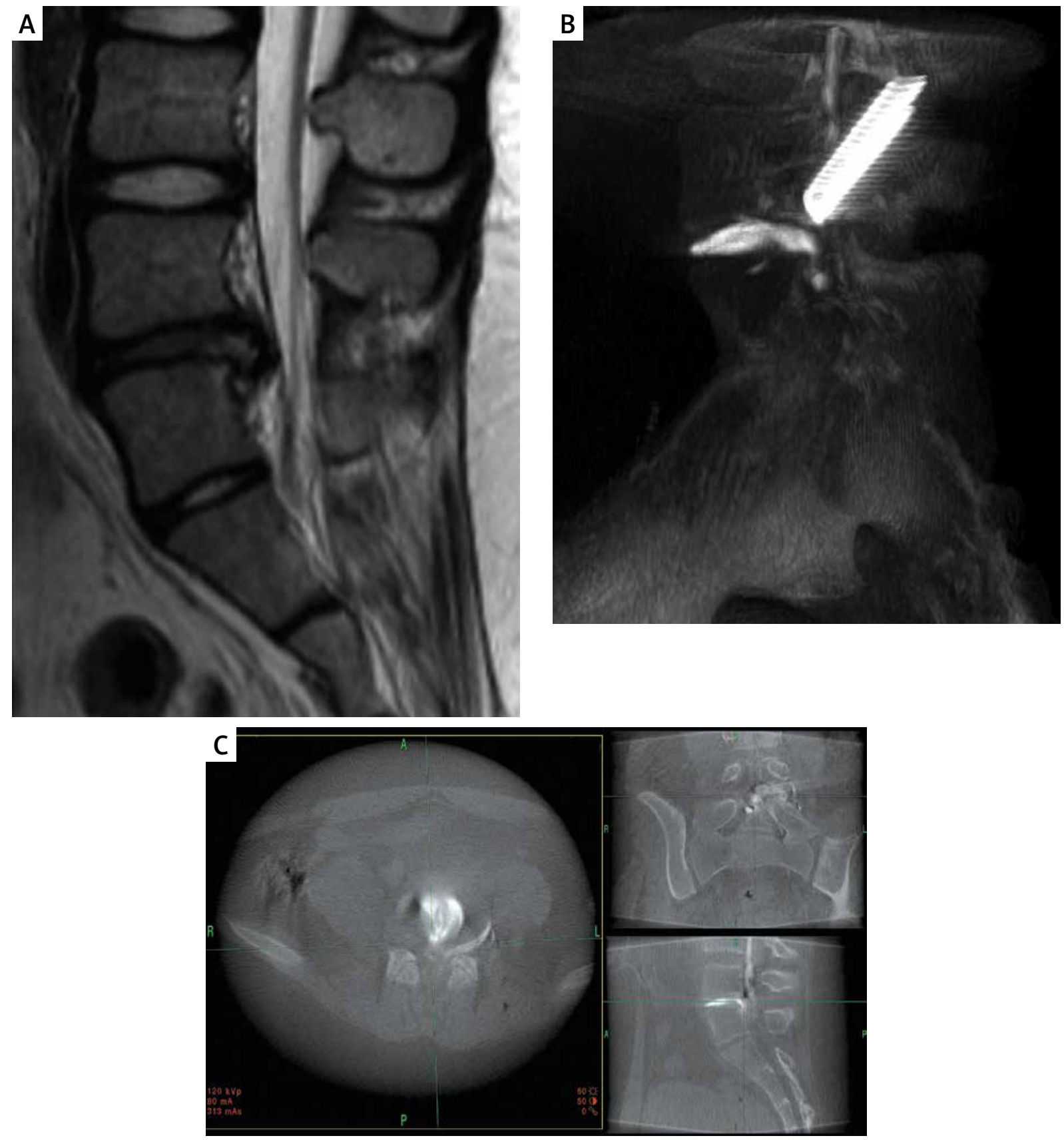

Photo 3. Images from a 23-year-old man who presented with severe left leg pain. A - T2-weighted sagittal magnetic resonance image showing a down-migrated disc herniation at L5-S1. B - Intraoperative 3D reconstruction of discogram showing location of the herniated disc. The working trajectory was set at the herniated disc. C - Intraoperative computed tomography scans of the spine show the multiplanar discography. The discography in axial view reveals an annular tear with extension to the outer annulus

Our experience is that the O-arm can be applied for PELD in most standard operating rooms. It is compact and mobile, and its effect on the operative room workflow is minor. Although intraoperative magnetic resonance imaging has been used at select institutions for PELD, it is more costly and time consuming, which precludes its widespread adoption [20]. In addition, the $\mathrm{O}$-arm is well suited to evaluate bony structures and results of the discography, helping surgeons to distinguish clearly disc tissue from 
Table I. Clinical characteristics of patients who underwent PELD with O-arm*

\begin{tabular}{|lc|}
\hline Parameter & Result \\
\hline Subjects, $n(\%)$ & $85(100)$ \\
\hline Age, mean \pm SD [years] & $62.5 \pm 12.7$ \\
\hline $\begin{array}{l}\text { Gender, } n(\%): \\
\text { Male }\end{array}$ & $44(51.8)$ \\
\hline Female & $41(48.2)$ \\
\hline Herniation location, $n(\%):$ & $27(31.8)$ \\
\hline Central & $30(35.3)$ \\
\hline Faracentral & $28(32.9)$ \\
\hline Level, $n(\%):$ & $8(9.5)$ \\
\hline L3-L4 & $63(74)$ \\
\hline L4-L5 & $14(16.5)$ \\
\hline L5-S1
\end{tabular}

${ }^{*} N(\%)$, unless indicated otherwise.

calcifications and ossifications, and especially for tailoring facet joint resections.

Nevertheless, the O-arm has certain limitations. There is a slight increase in radiation exposure and financial cost to the patient. However, the improvements in PELD afforded by better accuracy may reduce radiation frequency and operative time, which avoids additional hospital costs. The O-arm also does not allow satisfactory visualization of soft tissues. In the future, we hope a similar device may provide sufficient resolution of low-density structures, which could be useful in assessing the remnant of herniated disc tissue. We also note that this study is a retrospective follow-up, and a randomized controlled trial should be performed to compare the efficiency and accuracy of the $\mathrm{O}$-arm with that of conventional fluoroscopy during PELD.

\section{Conclusions}

Herein we described our technique for establishing a working trajectory for PELD, using the O-arm. Initial results indicate that the procedure is safe and feasible. This machine provides important details in the intraoperative multiplanar view, which cannot be obtained by fluoroscopy. The 3D reconstruction discography image improves surgical accuracy and
Table II. Summary of modified MacNab's criteria

\begin{tabular}{|ll|}
\hline Outcome & \multicolumn{1}{c|}{ Description } \\
\hline Excellent & No pain and no restriction of activity \\
\hline Good & $\begin{array}{l}\text { Occasional pain, relief of presenting symp- } \\
\text { toms, able to return to modified work }\end{array}$ \\
\hline Fair & $\begin{array}{l}\text { Handicapped by intermittent pain of suffi- } \\
\text { cient severity to curtail work or leisure activity } \\
\text { but improved functional capacity }\end{array}$ \\
\hline Poor & $\begin{array}{l}\text { Unimproved symptoms, insufficient improve- } \\
\text { ment to allow increased activity, or requires } \\
\text { reoperation at the same level }\end{array}$ \\
\hline
\end{tabular}

is an effective option in anatomically challenging cases.

\section{Conflict of interest}

The authors declare no conflict of interest.

\section{References}

1. Kambin P, Gellman H. Percutaneous lateral discectomy of the lumbar spine a preliminary report. Clin Orthop Relat Res 1983; 174: $127-32$.

2. Gibson JN, Cowie JG, Iprenburg M. Transforaminal endoscopic spinal surgery: the future 'gold standard' for discectomy? A review. Surgeon 2012; 10: 290-6.

3. Webb J, Gottschalk L, Lee YP, et al. Surgeon perceptions of minimally invasive spine surgery. SAS J 2008; 2: 145-9.

4. Wang $H$, Huang B, Li C, et al. Learning curve for percutaneous endoscopic lumbar discectomy depending on the surgeon's training level of minimally invasive spine surgery. Clin Neurol Neurosurg 2013; 115: 1987-91.

5. Mattei TA, Fassett DR. Letter to the editor: The O-arm revolution in spine surgery. J Neurosurg Spine 2013; 19: 644-7.

6. Kim DG, Lee SH, Transforaminal surgical approach. In: Endoscopic spine procedures. Kay Conerly K (ed.). Thieme Medical Publishers, Inc. New York, NY 2011; 129-42.

7. MacNab I. Negative disc exploration an analysis of the causes of nerve-root involvement in sixty-eight patients. Bone Joint J 1971; 53: 891-903.

8. Choi I, Ahn JO, So WS, et al. Exiting root injury in transforaminal endoscopic discectomy: preoperative image considerations for safety. Eur Spine J 2013; 22: 2481-7.

9. Kubaszewski L, Kaczmarczyk J, Nowakowski A, et al. Foraminoplastic transfacet epidural endoscopic approach for removal of intraforaminal disc herniation at the L5-S1 level. Videosurgery Miniinv 2014; 9: 96-100.

10. Lee SH, Kang HS, Choi G, et al. Foraminoplastic ventral epidural approach for removal of extruded herniated fragment at the L5-S1 Level. Neurol Med Chir 2010; 50: 1074-8.

11. Choi G, Lee SH, Lokhande P, et al. Percutaneous endoscopic approach for highly migrated intracanal disc herniations by foraminoplastic technique using rigid working channel endoscope. Spine 2008; 33: E508-15. 
12. Sembrano JN, Santos ERG, Polly DW. New generation intraoperative three-dimensional imaging (O-arm) in 100 spine surgeries: does it change the surgical procedure? J Clin Neurosci 2014 21: 225-31.

13. Del Curto D, Kim JS, Lee SH. Minimally invasive posterior cervical microforaminotomy in the lower cervical spine and C-T junction assisted by $\mathrm{O}$-arm-based navigation. Comput Aided Surg 2013; 18: 76-83.

14. Guyer RD, Ohnmeiss DD. Lumbar discography. Spine J 2003; 3: 11s-27s.

15. Maus TP, Aprill CN. Lumbar discogenic pain, provocation diskography, and imaging correlates. Radiol Clin North Am 2012; 50: 681-704.

16. Zhou YL, Abdi S. Diagnosis and minimally invasive treatment of lumbar discogenic pain - a review of the literature. Clin J Pain 2006; 22: 468-81.

17. Choi KC, Kim JS, Kang BU, et al. Changes in back pain after percutaneous endoscopic lumbar discectomy and annuloplasty for lumbar disc herniation: a prospective study. Pain Med 2011; 12: 1615-21.

18. Lee SH, Kang HS. Percutaneous endoscopic laser annuloplasty for discogenic low back pain. World Neurosurg 2010; 73: 198206.

19. Kluner C, Kivelitz D, Rogalla P, et al. Percutaneous discography: comparison of low-dose CT, fluoroscopy and MRI in the diagnosis of lumbar disc disruption. Eur Spine J 2006; 15: 620-6.

20. Choi G, Modi HN, Prada N, et al. Clinical results of XMR-assisted percutaneous transforaminal endoscopic lumbar discectomy. J Orthop Surg Res 2013; 8: 14.

Received: 6.06.2015, accepted: 20.10.2015. 